University of New Mexico

UNM Digital Repository

Shared Knowledge Conference

Nov 8th, 11:00 AM - 1:00 PM

\title{
Tracing transmission of Sin Nombre Virus and discovery of infection in multiple rodent species
}

Samuel Goodfellow

University of New Mexico

Follow this and additional works at: https://digitalrepository.unm.edu/skc

Goodfellow, Samuel. "Tracing transmission of Sin Nombre Virus and discovery of infection in multiple rodent species." (2021). https://digitalrepository.unm.edu/skc/2021/Posters/35

This Event is brought to you for free and open access by UNM Digital Repository. It has been accepted for inclusion in Shared Knowledge Conference by an authorized administrator of UNM Digital Repository. For more information, please contact disc@unm.edu. 
Tracing transmission of Sin Nombre Virus and discovery of infection in multiple rodent species

Samuel M. Goodfellow, Doctoral Candidate, Biomedical Sciences Graduate Program (BSGP), University of New Mexico - Health Sciences Center

Robert A. Nofchissey, University of New Mexico - Health Sciences Center

Kurt C. Schwalm, University of New Mexico - Health Sciences Center

Joseph A. Cook, PhD University of New Mexico

Jonathan L. Dunnum, PhD University of New Mexico

Yan Guo, PhD University of New Mexico - Health Sciences Center

Chunyan Ye, University of New Mexico - Health Sciences Center

Gregory J. Mertz, MD University of New Mexico - Health Sciences Center

Kartik Chandran, $\mathrm{PhD}$ Albert Einstein College of Medicine

Michelle Harkins, MD University of New Mexico - Health Sciences Center

Daryl B. Domman, PhD University of New Mexico - Health Sciences Center

Darrell L. Dinwiddie, PhD University of New Mexico - Health Sciences Center

Steven B. Bradfute, PhD University of New Mexico - Health Sciences Center

Orthohantaviruses are a family of negative-sense, single-stranded segmented RNA viruses that can cause hantavirus cardiopulmonary syndrome (HCPS) throughout North, Central and South America. Transmission of these viruses is primarily through exposure to droppings from infected rodents. Sin Nombre virus (SNV), found in North America, is primarily carried, and transmitted, by deer mice (Peromyscus maniculatus) and has a $\sim 36 \%$ case fatality rate in humans. New Mexico has the highest number of human SNV cases in the United States making it important to understand the distribution and genetics of SNV within this region. In August 2020, amidst the severe acute respiratory syndrome coronavirus 2 (SARS-CoV-2) pandemic, a patient entered the University of New Mexico Hospital for SNV infection while testing negative for SARS-CoV2. Using a diagnostic tool established in the lab, we confirmed SNV infection through reversetranscriptase quantitative polymerase chain reaction (RT-qPCR). However, it was uncertain exactly where the patient's exposure to SNV occurred, so we investigated two sites using trapping methods to capture rodents at both locations. We screened rodent lung samples for SNV infection and developed an in-house protocol for viral whole-genome sequencing for SNV. Using phylogenetic analysis, we found we could correlate the most likely site for patient transmission while also discovering SNV infection in multiple rodent species in addition to Peromyscus maniculatus. We propose using this method to increase the understanding of genetic variations of SNV and provide insight into hantavirus disease epidemiology within New Mexico. 